\title{
Acute pulmonary embolism following air travel
}

\author{
J. A. LEDERMANN* \\ B.Sc., M.B., M.R.C.P.
}

\author{
ALI KESHAVARZIAN \\ M.D., M.R.C.P.
}

Hillingdon Hospital, Uxbridge, Middlesex

\section{Summary}

Three cases of pulmonary embolism following long air flight are described. There was no previous history of venous disease. The symptoms were transient in one and severe in two. The occurrence of pulmonary embolism immediately after air travel is emphasized.

KEY WORDS: pulmonary embolism, air travel.

\section{Introduction}

Pulmonary embolism in travellers has been described (Beighton and Richards, 1968; Horsley, Smail and Thould, 1975; Symington and Stack, 1977), but only occasionally has it been associated with travel by air. Increase in air travel, longer flights and the carriage of passengers who are unfit may cause this event, now rare but probably underdiagnosed, to occur more often. Cardiovascular morbidity following air travel was reviewed by Beighton and Richards (1968), and arterial thrombosis following air travel has recently been reported (Collins, Field and Castleden, 1979). We describe 3 cases of acute pulmonary embolism in air travellers admitted to this hospital which is one that serves London Airport (Heathrow).

\section{Case 1}

A 66-year-old woman was admitted following the sudden onset of dyspnoea as she walked off the plane from Australia. She had no chest pain, but felt faint. She had had mild pain in her right knee during the flight. On examination she was obese; cyanosis had been noticed at the airport but physical examination at the hospital was normal. The electrocardiogram showed an $S_{1} Q_{3} T_{3}$ pattern with $T$ wave inversion in leads $V_{1}-V_{3}$ but the chest $X$-ray was normal. A ventilation-perfusion scan showed multiple perfusion defects. She was treated with anticoagulants and recovered. 6AU.

\section{Case 2}

A 59-year-old woman became severely breathlessir on leaving the aircraft on a flight from Zimbabwe On arrival at the hospital she was in asystole, anco although initial resuscitation was successful she died a few hours later. She was known to have carcinomas of the breast with cutaneous and pulmonary spread? producing pleural effusions. The diagnosis of pulmo $=$ nary embolism from thrombosis in the calf veins wasT made at post-mortem.

\section{Case 3}

A 63-year-old woman was admitted following flight from Auckland on account of dyspnoea a pleuritic chest pain on alighting from the aircraft She had experienced swelling of her legs during the flight. On examination she was cyanosed, blooø̋ pressure $90 / 60 \mathrm{mmHg}$, the heart rate was 110 per min, the jugular venous pressure was elevated and the heart sounds were normal. Bilateral basal crepita $\frac{0}{3}$ tions and pitting oedema of the feet were present The electrocardiogram showed an $S_{1} Q_{3} T_{3}$ pattern and the chest $\mathrm{X}$-ray was normal. Arterial blood analysis showed a reduced $\mathrm{PO}_{2}(6.0 \mathrm{kPa})$ and normaB $\mathrm{PCO}_{2}(5.4 \mathrm{kPa})$, the blood urea was slightly raised ato $8.5 \mathrm{mmol} /$ litre. A perfusion scan showed multiple 3 . filling defects. She was treated with anticoagulants and recovered.

\section{Comment}

Previous reports have shown that there is a delay of at least $48 \mathrm{hr}$ in presentation (Symington and Stack, 1977). In the cases described, breathlessnesse developed as the patients moved to get off the planew after their prolonged immobility, supporting the view that fresh clot, formed on the flight, was responsibleso Risk factors were known to exist in only one patient $\mathbb{\Phi}$ Other reported cases had evidence of previous venous disease (Symington and Stack, 1977). It seems ${ }^{0}$ likely that cramped seating for prolonged periods 
with pressure on the popliteal and femoral veins may have led to the formation of clot (Homans, 1954). Venous flow has been shown to be halved in the sitting position (Paylin, Wright and Osborn, 1952). During flight dehydration occurs (Carruthers, Arguelles and Mosovich, 1976) and is sometimes exacerbated by alcohol consumption. One of our patients had an elevated urea on admission.

Symington and Stack (1977) found 3 cases of pulmonary embolism following air travel out of 182 cases of pulmonary embolism admitted during a 3 -year period. The analysis of admissions from Heathrow Airport to Hillingdon Hospital from 1963 to 1965 by Beighton and Richards (1968) revealed only one such case. Simple preventive measures such as adequate fluid intake and mobilization during the flight should be encouraged, particularly in those at special risk. Medical personnel at the airport should be aware of the possible significance of transient dyspnoea.

\section{Acknowledgments}

We are grateful to Dr A. H. James and Dr L. H. Sevitt for their permission to report their patients.

\section{References}

Beighton, P.H. \& RiChaRd, P.R. (1968) Cardiovascular disease in air travellers. British Heart Journal, 30, 367.

Carruthers, M., Arguelles, A.E. \& Mosovich, A. (1976) Man in transit: Biochemical and physiological changes during intercontinental flights. Lancet, i, 977.

Collins, R.E.C., Field, S. \& Castleden, W.M. (1979) Thrombosis of leg arteries after prolonged travel. British Medical Journal, 2 , 1478.

Homans, J. (1954) Thrombosis of deep leg vein due to prolonged sitting. New England Journal of Medicine, 250, 148.

Horsley, S.E., Smail, P.J. \& Thould, A.K. (1975) Effects of influx of holiday makers on an acute medical unit in Cornwall. British Medical Journal, 4, 276.

PAYlin, G., WRIGHT, H. \& OSBORN, S.B. (1952) Effect of posture on venous velocity measured with ${ }^{24} \mathrm{NaCl}$. British Heart Journal, 14, 325.

Symington, I.S. \& STACK, B.H.R. (1977) Pulmonary thromboembolism after travel. British Journal of Diseases of Chest, 71, 138.

(Accepted 11 June 1982) 